\title{
DOS EFEITOS DA DECLARAÇÃO DE DISTINTIVIDADE ADQUIRIDA
}

\author{
EFFECTS OF THE DECLARATION OF ACQUIRED DISTINCTIVENESS \\ DENIS BORGES BARBOSA
}

Professor doutor da UERJ

\section{RESUMO}

Cabe aqui ponderar sobre um tema interessante: uma vez que se determina a existência dos pressupostos de fato que justificam a aquisição subsequente de distintividade, o que acontece? O próprio conceito do instituto ajuda a resposta. Se há aquisição de distintividade por uso e consagração, presume-se originalmente não haveria fundamento para conceder a exclusividade pretendida, ou então tal proteção seria limitada pela baixa radiação significativa inicial.

Palavras-chaves: Efeitos. Declaração. Dinstintividade.

ABSTRACT

It should be an interesting topic to ponder: since it determines the existence of the assumptions of fact which justify the subsequent acquisition of distinctiveness, what happens? The concept of the institute itself helps to answer. If no acquisition of distinctiveness through use and consecration, it is assumed there would be no basis for originally granting the desired exclusivity, or such protection would be limited by the low initial significant radiation.

Key Words: Effects. Statement. Dinstintividade.

Cabe aqui ponderar sobre um tema interessante: uma vez que se determina a existência dos pressupostos de fato que justificam a aquisição subsequente de distintividade, o que acontece?

O próprio conceito do instituto ajuda a resposta. Se há aquisição de distintividade por uso e consagração, presume-se originalmente não haveria fundamento para conceder a exclusividade pretendida, ou então tal proteção seria limitada pela baixa radiação significativa inicial.

Assim, não há nulidade do ato administrativo que não reconheceu a exclusividade; ao momento da apreciação dos requisitos de registro, a autoridade pública não errou. Assim como acontece - reversamente - no fenômeno da generificação ${ }^{1}$, há um fenômeno posterior e que altera a

\footnotetext{
1 Sobre a questão da generificação, vide o nosso Proteção das Marcas, Lumen Juris, 2007, p. 104, 4.2.1. Patologia da fama, transcrito em grande parte no estudo, em coautoria com Elaine Ribeiro do Prado, Generificação e Marcas Registradas, encontrado em http://denisbarbosa.addr.com/generifica.pdf. No livro, assim notamos: "Ao mesmo tempo em que o titular da marca generificada detém um quase-monopólio no
} 
substância do direito. Na generificação, há uma perda do objeto do direito, que pode subtrair a base jurídica da concessão da exclusividade. Aqui, haverá um ganho qualitativo:

a) Ou o signo ao qual faltava o requisito da distintividade, passou a tê-la;

b) Ou aquele que tinha tênue distinguibilidade, ganha robustez e aumenta sua penumbra de proteção.

Assim, à falta de um instrumento de direito administrativo que permita a mutação do registro, ou sua admissão, a intervenção judicial tem o efeito de declarar a situação de fato, e comandar a alteração do registro ${ }^{2}$.

\section{Distintividade após a criação e distintividade após o registro}

Como não se tem- na hipótese em estudo - de corrigir um ato administrativo nulo, mas sim de se adaptar às mutações do objeto do registro, assim também não haverá efeitos ex tunc na declaração. $\mathrm{O}$ ato judicial, mediante consideração das provas produzidas, poderá concluir que a certa data, a marca adquirira suficiente distintividade para mudar o status, ou ser admitido a registro.

Declarada a aquisição de distintividade, se resolve uma questão vertical: a do

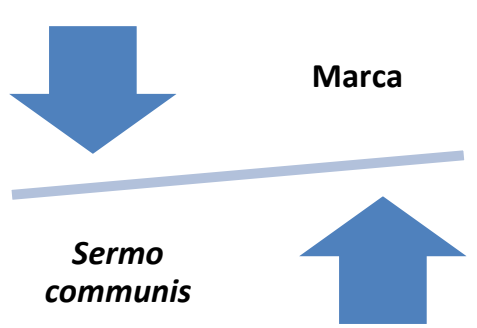
distanciamento do signo em face do domínio comum. Pois, como já se demonstrou, a falta de distintividade que se cura com o secondary meaning é a demasiada proximidade, ou mesmo a fusão, com o sermo communis.

Outra

item designado, arrisca-se a perder totalmente a

Marca

doutrina francesa: «Il faut observer qu'initialement, wus Ies eIl

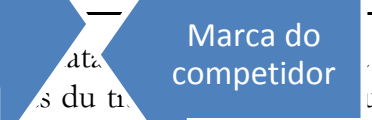

razão". E cito a le tende à susciter cette évolution. Les avantages économiques qu'il en retire sont,, $\mathrm{n}$ effet, $\mathrm{cc}$ dérables. Plus le signe adopté à titre de marque se généralise et s'identifie au produit, plus la notoriété de la starque est solide et durable. En entretenant la confusion de la marque et de l'objet, le producteur s'assure un véritable monopole de fabrication. Il suffit imaginer comment les choses se passent en pratique. Le consommateur, pour lequel la marque est devenue la désignation générique du produit, le réclame sous cette dénomination; mais le commerçant qui, en principe ne partage pas l'ignorance de l'acheteur, ne peut livrer qu'une marchandise ayant une origine déterminée. Il en résulte que, sous le couvert d'une appellation à laquelle le public n'attache plus de signification particulière, les produits d'un seul fabricant se vendent au détriment de ceux des producteurs concurrents. (La dégénérescence des marques par excès de notoriété, in: Mélanges en l'honneur de Daniel Bastian, Paris, Librairies Techniques, vol.2, p.50). Uma atualização do tema se encontra em Nota sobre a concessão de direitos exclusivos sobre sinais genéricos ou descritivos (novembro de 2011), encontrado em http://www.denisbarbosa.addr.com/arquivos/200/propriedade/concessao_direitos_exclusivos.pdf.

${ }^{2}$ Quando se tratar de alteração de registro já existente, tal comando se fará através de anotação, na forma do art. 136: O INPI fará as seguintes anotações: I - da cessão, fazendo constar a qualificação completa do cessionário; II - de qualquer limitação ou ônus que recaia sobre o pedido ou registro; e III - das alterações de nome, sede ou endereço do depositante ou titular. A limitação, no caso, será do apostilamento ou de outro elemento do registro que constranja a exclusividade. 
questão, e muito diversa, é da distintividade horizontal, ou entre usuários no mercado do mesmo signo, ou similar a ponto de confusão ou associação.

$\mathrm{Na}$ doutrina elaborada em torno da legislação europeia relativa ao registro de marcas, dizem-se esses dois aspectos os impedimentos absolutos (vertical) e relativos (horizontal) ao registro. É outra forma de expressar o mesmo.

A apuração de distintividade subsequente presume reconhecer que o público - ou parcela significativa dele - associa a o signo a uma origem determinada, conferindo àquele uso do signo uma carga diversa daquela atribuída ao uso genérico do mesmo significante. Para que isso aconteça, é necessário que haja, além de fatores tipicamente semiológicos (o reconhecimento de origem) também um fator concorrencial, qual seja, o signo que passa a denotar uma certa origem tem de distinguir tal origem das outras origens possíveis do mesmo bem ou serviço.

Em outras palavras, a prova de distintividade vertical adquirida indica um determinado grau mínimo de distintividade horizontal. Mas não exclui, em abstrato, a possibilidade de interesses de concorrentes serem afetados pela distintividade gerada e adquirida no decorrer da criação do fundo de comércio pelo beneficiário do secondary meaning ${ }^{3}$.

\section{O momento da aquisição de distintividade}

O momento da fixação do momento em que a distintividade se adquire é assim relevante. É o instante (pois se trata de distintividade posterior à criação da marca) em que o signo ganha potencial de tornar-se excludente de terceiros e obtido o registro - de tornar-se exclusiva ${ }^{4}$.

Num pleito em que se discutia a nulidade do ato administrativo do Escritório Europeu de Marcas e Desenhos Industriais, o Tribunal de Primeira Instância da União estabeleceu precedente no caso eCopy, bastante citado, segundo o qual - para os efeitos de suspender a causa absoluta de recusa de registro (falta de distintividade) a aquisição deve ser provada que ocorreu no mercado antes

\footnotetext{
3 O âmbito da distintividade pode não ser em escala nacional, pois não se trata no caso de definição dos efeitos do alto renome ou da notoriedade, mas simplesmente de determinar que a marca ultrapassou um grau mínimo de distintividade que lhe garanta a proteção normal; e não superproteção extraclasse ou supra territorial. Vide: "Although plaintiff has demonstrated that its mark has acquired secondary meaning within the specific neighborhoods in which it has branches, it has not made the necessary showing beyond those areas. Accordingly, its mark is enforceable within Allston /Brighton, Brookline, Jamaica Plain, Norwood and West Roxbury areas but not throughout all of Eastern Massachusetts or even the rest of Middlesex , Suffolk and Norfolk counties." Peoples Federal Savings Bank, V. People's United Bank, 750 F. Supp. 2d 217(2010).

4 "Most courts apply the rule that the senior user must prove the existence of secondary meaning in its mark just prior to the time and place that the junior user first began use of that mark. 505 U.S. 1244, 120 L. Ed. 2d 947, 113 S. Ct. 20 (1992)." McCarthy, cit. \ 15:4 Time of acquisition of secondary meaning
} 
ISSN ELETRÔNICO 2316-8080

DENIS BORGES BARBOSA

do registro que se postula 5 . Só assim pode-se avaliar a nulidade, ou não do ato do registrador.

O caso em estudo, porém, não se refere à nulidade do ato administrativo do órgão registrador. $\mathrm{Na}$ verdade, o que se considera aqui são os efeitos do aumento de distintividade após o registro e o apostilamento. Assim, inaplicável ao caso o ensinamento europeu, embora intelectualmente relevante para as hipóteses em que se pretende superar uma recusa inicial do INPI com base em falta de distintividade originária.

Aqui a declaração de aquisição de distintividade poderá remontar ao momento de fato em que o que era do domínio comum emerge e se torna suscetível à apropriação singular. Intuitivamente, tal fato poderá ter ocorrido no momento em que se efetua a verificação de fato, ou remontar-se a tempo anterior, naquilo que os meios de prova forem suficientes para isso ${ }^{6}$. À falta de tal determinação, e tendo em vista os limites da provisão judicial pretendida, o

\footnotetext{
5 "36.O artigo 7., $\mathrm{n}^{\circ}$ 3, do Regulamento $\mathrm{n}^{\circ} 40 / 94$ deve ser interpretado no sentido de que o carácter distintivo de uma marca deve ter sido adquirido por um uso anterior à apresentação do pedido. Por conseguinte, a circunstância de uma marca ter adquirido carácter distintivo por um uso posterior à data de apresentação do pedido e anterior ao momento em que o IHMI, isto é, o examinador ou, eventualmente, a Câmara de Recurso, decide sobre a questão de saber se existem motivos absolutos de recusa que obstam ao registo dessa marca é destituída de pertinência. De onde se conclui que qualquer prova relativa ao uso posterior à data de apresentação do pedido não pode ser tida em consideração pelo IHMI. 37. Com efeito, em primeiro lugar, esta interpretação é a única compatível com a coerência do sistema dos motivos absolutos e relativos de recusa em matéria de registo de marca comunitária. Como decorre do artigo $8 .^{\circ}, \mathrm{n}^{\circ} 2$, alíneas a) e b), do Regulamento $n^{\circ} 40 / 94$, a data de apresentação do pedido, tal como é definida no artigo $26 .^{\circ}$ do mesmo regulamento, determina a prioridade de uma marca em relação a outra. Note-se que, se uma marca que só tivesse adquirido carácter distintivo pelo uso posteriormente à apresentação do pedido fosse, ainda assim, registada, poderia servir de base à aplicação, no quadro de uma oposição ou de um pedido de anulação, de um motivo relativo de recusa contra outra marca cuja data de apresentação fosse posterior à da primeira marca. Esta situação poderia ocorrer ainda que, na data da apresentação da segunda marca, já com carácter distintivo nessa data, a primeira ainda não tivesse adquirido carácter distintivo pelo uso e não preenchesse os requisitos necessários para ser registada. Ora, este resultado seria inaceitável." Acórdão do Tribunal de Primeira Instância (Quarta Secção) de 12 de Dezembro de 2002 T-247/01, eCopy, Inc., encontrado em http:/ / curia.europa.eu/juris/document/document.jsf?text=\&docid=47611\&pageIndex=0\&doclang=PT\&m ode $=1$ st\&dir $=\&$ occ $=$ first \&part $=1 \& \operatorname{cid}=5866147$, visitado em $79 / 2013$.
}

${ }^{6} \mathrm{O}$ que se apurará é se houve a aquisição de distintividade, e não simplesmente dos esforços do titular da marca em obtê-la: o dever é de resultado, e não de meio: "For a brief period of time from the mid 1970's to the early 1990's some of the district courts in the Second Circuit began to speak of a doctrine which they labeled "secondary meaning in the making." In these case, the plaintiff would be using a descriptive term or symbol to designate its goods and services, and would be expending money and effort to build consumer recognition and establish secondary meaning. Before secondary meaning could actually be proved, however, the defendant would enter the market and deliberately begin using the same descriptive designation or one closely similar to it. Troubled by the supposedly unsavory nature of these defendants' conduct, the court would afford relief to the plaintiff despite the absence of secondary meaning. In the 1992 case of Laureyssens v. Idea Group, Inc., the Second Circuit clearly rejected the doctrine, observing that "the so-called doctrine of secondary meaning in the making, by affording protection before prospective purchasers are likely to associate the [mark] with a particular sponsor, constrains unnecessarily the freedom to copy and compete." The result in Laureyssens is consistent with the approach taken by other federal appellate courts around the country as well as with the views of commentators on the subject. The doctrine of "secondary meaning the making" has not been much heard from since the mid-nineties and is best viewed now as a historical curiosity.' SCHECHTER, Roger E. e THOMAS, John R. Intellectual Property The Law Of Copyrights, Patents And Trademarks. Ed. Thomson West. 2003. USA. P. 591 
efeito será obtido ao momento em que a pretensão é deduzida no processo pertinente.

\section{O efeito horizontal da declaração}

Distinguimos acima o efeito excludente da distintividade adquirida, e o efeito exclusivo. Ao se tornar - perante o público relevante - sinal de origem e não só representativo genérico do produto ou serviço, a marca criou necessariamente um espaço próprio, que competidores não podem entrar com marcas assimiláveis, sem incorrer em concorrência desleal por confusão ou associação.

Com efeito, o reconhecimento do público que o símbolo é sinal de origem é um requisito para que se tenha marca de fato, ou, mais precisamente, que se adquira marca de fato. Assim dissemos em estudo recente ${ }^{7}$ :

Como diz, num trecho extremamente habilidoso, José de Affonseca Gusmão em sua tese doutoral ${ }^{8}$ :

“ (...) a utilização protegível de uma marca não registada é sujeita a uma quinta condição, que é o resultado da utilização. É necessário que o uso do sinal para produzir um determinado resultado de ser protegível, e este resultado é se traduz pela congregação de uma clientela (ralliement de la clientèle).

A reunião da clientela é efetivamente o valor econômico e moral que se destina a ser protegida pelo direito. Em todas as decisões judiciais que têm reconhecido a proteção às marcas de uso, encontramos um terreno comum: o de evitar a confusão entre os produtos por parte da clientela (ou consumidor). O que se pretende evitar, em última análise, é que a clientela tome um produto como sendo um outro. No entanto, o objetivo da repressão da concorrência desleal não é o da defesa do consumidor, mas a proteção da boa fé entre comerciantes e um mercado saudável e honesto. Assim, para que haja confusão ou um risco de confusão, se

\footnotetext{
${ }^{7}$ BARBOSA, Denis Borges, Da proteção real da marca não registrada no Brasil (janeiro de 2013), encontrado em http://www.denisbarbosa.addr.com/arquivos/200/propriedade/da_protecao_real_marca_nao_registrada.pd $\mathrm{f}$

8 "(...) l'usage protégeable d'une marque non enregistrée est soumis à une cinquième condition, qui est celle du résultat de l'usage. Il faut en effet que l'usage de la marque produise un certain résultat pour être protégeable, et ce résultat se traduit par le ralliement de la clientèle. Le ralliement de la clientèle constitue effectivement la valeur économique et morale que l'on vise à protéger par le droit. Dans toutes les décisions de jurisprudence qui ont reconnu une protection aux marques d'usage, l'on trouve un fondement commun: celui d'éviter la confusion des produits de la part de la clientèle (ou du consommateur). Ce que l'on veut éviter, en définitive, est que la clientèle prenne un produit pour un autre. Or, le but de la répression par la concurrence déloyale n'est pas celui de la protection du consommateur, mais celui de la protection des commerçants de bonne foi, et d'un marché sain et honnête. Ainsi, pour qu'une confusion ou une possibilité de confusion soit établie, le ralliement de la clientèle autour de la marque est un fait supposé. En effet, il n'y a pas de confusion possible, même si l'on est en présence de marques identiques, si l'une de ces marques n'est pas connue de la clientèle, et ne motive pas la préférence de celle-ci. Manquerait alors l'acteur principal de la confusion ou tromperie: la clientèle." Gusmão, cit. p. 146-147.
} 
pressupõe a congregação de uma clientela (ralliement de la clientèle) em torno da marca. Na verdade, não há confusão possível, mesmo que se está na presença de marcas idênticas, se uma destas marcas não é conhecida pela clientela, e não motiva a preferência dela. Se fosse assim, faltaria o ator principal da confusão ou engano: a clientela.

E, no mesmo texto, cuidando dos efeitos excludentes dessa aquisição como consagrado pelos precedentes:

"No que diz com a alegação de que a querelante não detém legitimidade para a propositura da ação por não possuir o registro da marca que leva a expressão And Landscape Design, é de se notar que a hipótese dos autos, evidentemente, não versa sobre acusação de crime contra marcas ou patentes, mas sim, como visto, de concorrência desleal, delito previsto no artigo 195 da Lei no 9.279/96 (...) Assim, a circunstância de a empresa querelante não possuir o registro da marca não constitui óbice à deflagração penal, visto que o objeto material, no caso, não é proteção à marca, que tem sede própria nos artigos 189 e 190 da Lei de regência, mas a liberdade de competir "com lisura e correção, sem lançar mão de expedientes desonestos ou desleais, respeitando o mínimo ético" (Nelson Hungria, in "Comentários", vol. VII, p. 380)". Superior Tribunal de Justiça, 6a Turma, Min. Paulo Galloti, RHC 15992/SP, DJ 08.06.2009.

Mas o efeito excludente é limitado:

"O ordenamento jurídico confere proteção aos detentores de marcas registradas, bem como àqueles que não procederam ao registro no INPI, mas tais defesas submetem-se a limites e requisitos, inclusive de ordem temporal". Tribunal de Justiça do Estado de Pernambuco, $4^{a}$ Câmara Cível, Des. Jones Figueiredo, AC 133994-0, Julgado em 03.06.2009.

"As circunstâncias do caso concreto reforçam a impressão do parasitismo. A marca "Amor aos Pedaços" goza de inegável apelo e prestígio junto ao público em geral, fruto de anos de investimentos e cuidado na elaboração e vendas de bolos e doces.

Pouco provável, diante da infinita variedade do léxico, que a ré, ao inaugurar doceria no interior de um shopping Center a menos de sessenta quilômetros de São Paulo, tenha escolhido o nome e a marca "Delícias em Pedaços" sem o propósito de beneficiar, de modo direto ou indireto, do prestígio da marca concorrente." TJSP, AC 396.623.4/2-00, Quarta Câmara de Direito Privado do Tribunal de Justiça do Estado de São Paulo, por votação unânime, julgamento 2 de abril de 2009.

E o efeito exclusivo? Esse se dá pelo poder de excluir concorrentes e não concorrentes, ou mais precisamente, tanto aqueles que se engajem em competição efetiva (e que podem, se a colisão resulta em confusão ou associação ilícita, serem cobertos pela concorrência desleal) quanto aqueles que, por estarem disputando outro mercado geográfico, ou ainda não terem ainda entrado no mercado, não seriam concorrentes desleais por não serem 
ISSN ELETRÔNICO 2316-8080

DOS EFEITOS DA DECLARAÇÃO DE DISTINTIVIDADE ADQUIRIDA

concorrentes ou por não serem... desleais. Pois o direito exclusivo exclui todos do uso da marca em todo território, irrelevante o conteúdo subjetivo.

\section{Quando o efeito exclusivo precede o registro}

Dir-se-ia, irrefletidamente, assim, que só pelo registro se obteria o efeito exclusivo da aquisição subsequente de distintividade. Mas tal não ocorre.

Remontando ao mesmo estudo:

A proteção promovida pelas regras de repressão à concorrência desleal é ativa e positiva, no sentido que ela provê reparação e interdição de conduta desleal. Mas, enfatizando o status jurídico das marcas não registradas, a lei igualmente garante a proteção passiva das marcas não registradas, impedindo que qualquer terceiro requeira e adquira a exclusividade de uma marca que está sendo usada por outra pessoa como marca de fato.

Isso se dá, essencialmente, pelos institutos do direito de precedência e da chamada exceşão Ponillet.

Com efeito, se o ganho de distintividade satisfaz os requisitos do direito de precedência, a marca de fato (que se tornou marca em se tornando distintiva) é suscetível de se tornar o núcleo das pretensões do direito de precedência?

Mas igualmente a marca que adquiriu distintividade torna-se protegida pela aplicação do 124, XXIII do CPI $/ 96^{10}$ :

"O dispositivo do art. 124, XXIII, foi introduzido pela LPI a fim de coibir a fraude à lei cometida por meio de apropriação de marca sabidamente alheia. Trata-se de importante ferramenta no combate à concorrência desleal. Inspirada pelos princípios da livre concorrência e proteção às marcas, esta regra aplica a exceção de má-fé, também conhecida como exceção Pouillet, que além de seu potencial efeito de extraterritorialidade, encerra um enunciado intrínseco de ilicitude. Assim, é eivada de ilicitude a ação daquele que visa apropriar-se, por meio do registro, de marca que sabe ser usada por terceiro para designar produto idêntico ou afim. (...)

No presente caso, ficou cabalmente comprovado o fato de que a MARCATIVA inequivocamente sabia do uso anterior da marca "VISUAL JEANS" pelas empresas ALAIR BARBARA FRONZA e VISUAL IND. E COM., tendo, inclusive, tentando "vender" a mesma a eles, além de ser possuidora de inúmeros pedidos de registros de marcas diversas, o que

9 Vide BARBOSA, Denis Borges, Direito de Precedência ao Registro de Marcas, in Usucapião de Patentes e outros estudos de Propriedade Intelectual, Lumen Juris, 2006, encontrado em http://denisbarbosa.addr.com/precedencia.pdf.

10 Vide BARBOSA, Denis Borges, Revendo a questão da exceção Pouillet (outubro de 2011) encontrado em http://www.denisbarbosa.addr.com/arquivos/200/propriedade/excecao_pouillet.pdf. Também, Nota Sobre o Disposto no Art. 124, XXIII, do CPI/96, in BARBOSA, Denis Borges. A Propriedade Intelectual no Século XXI - Estudos de Direito. Rio de Janeiro: Lumen Juris, 2008.

PIDCC, Aracaju, Ano III, Edição nº 06/2014, p.337-350 Jun/2014 | www.pidcc.com.br 
representa claro indício de tentativa de locupletamento indevido ao se apropriar de marcas para depois obter vantagem econômica com sua transferência para possíveis interessados, o que caracteriza verdadeiro ato de concorrência desleal". Tribunal Regional Federal da $2^{\mathrm{a}}$ Região, $2^{\mathrm{a}}$ Turma Especializada, J.C Márcia Maria Nunes de Barros, AC 2010.51.01.801200-3, DJ 04.0.2012.

Com efeito, se o uso de uma expressão antes insuscetível de proteção confere distintividade, e assim protectibilidade, a sua situação de marca de fato atrai todos os dispositivos legais de proteção desse ativo intangível. Inclusive, e especialmente, o afastamento das pretensões de quem pretende obter exclusividade para si a despeito da preexistência de marca de fato de terceiro.

\section{Aquisição posterior de distintividade de material apostilado}

1. Quais são os efeitos da aquisição subsequente de distintividade (secondary meaning) quanto a marca registrada com apostilamento, no tocante aos elementos objeto do apostilamento?

O elemento de uma marca registrada, que é sujeito a apostilamento por falta de distintividade, pode - como todos os elementos simbólicos -, ser objeto de ganho posterior de distintividade.

Uma vez que isso se dê e seja comprovado, tal elemento - que antes factualmente estava em domínio comum, ou tão próximo disso que não seria digno de apropriação singular -, passa a ser marca. Ainda não titulado em registro, passa a ser marca, ou elemento de marca de fato.

Assim, o que antes era um elemento de uso comum, emerge e se individualiza naquele uso específico como marca de fato, sem prejuízo do interesse do domínio comum para todos demais usos desse mesmo símbolo.

A exsurgência dessa marca de fato, como anteriormente indicado neste estudo, deflagra um conjunto de pretensões em favor de seu titular. A primeira delas é ser protegida pelos instrumentos da concorrência desleal. Ou seja, essa marca torna-se excludente do uso rival de outros concorrentes, no que suscetível de confusão e associação ilícita.

Mas também o fenômeno tem as consequências que a lei brasileira assegura para as marcas de fato, inclusive a proteção deferida pelo art. 129, parágrafo único, ao chamado direito de preferência. A marca de fato, uma vez que se configure dessa forma, pode opor-se a pretensão de terceiros, que posteriormente a sua constituição como marca de fato, depositem pedidos de proteção cujo objeto é colidente com a marca de fato. 
O segundo efeito de direito de uma marca de fato que se projeta além do domínio comum é - no direito brasileiro -, as consequências da aplicação do art., 124, XXIII, a chamada Exceção Pouillet:

\begin{abstract}
XXIII - sinal que imite ou reproduza, no todo ou em parte, marca que o requerente evidentemente não poderia desconhecer em razão de sua atividade, cujo titular seja sediado ou domiciliado em território nacional ou em país com o qual o Brasil mantenha acordo ou que assegure reciprocidade de tratamento, se a marca se destinar a distinguir produto ou serviço idêntico, semelhante ou afim, suscetível de causar confusão ou associação com aquela marca alheia.
\end{abstract}

Com efeito, uma vez que o elemento antes genérico virou marca de fato, ele dá azo à proteção em questão, que essencialmente cobre marcas de fato de terceiros, em face de pretensões de terceiros ao registro de marca confrontante, "que o requerente evidentemente não poderia desconhecer em razão de sua atividade". É esse a causa da proteção do inciso em questão: a proteção da marca de fato de terceiros, quando o depositante não podia deixar de conhecer a marca sênior.

Assim, cabe responder que os efeitos da aquisição subsequente de distintividade (secondary meaning) quanto a marca registrada com apostilamento, no tocante aos elementos objeto do apostilamento são, pelo menos, os seguintes:

1. Habilita o titular do elemento apostilado a dele utilizar-se como marca de fato, ou como elemento de marca de fato.

2. Garante ao titular da marca de fato ao efeito excludente que resulta da repressão à concorrência desleal.

3. Faculta à marca de fato deflagrar os efeitos previstos no art. 129, parágrafo único, do CPI/96, ou seja, o direito de precedência.

4. Faculta ao titular da marca de fato a obter, na forma do respectivo dispositivo legal, a proteção do art. 124, XXIII, ou exceşão Pouillet.

\title{
O efeito da marca de fato quanto a marca júnior essencialmente idêntica
}

O uso de um elemento de domínio comum é livre a todos, sem exceção e sem limites. Faz parte da liberdade geral econômica, garantida pelo art. 1, IV e 170 da Constituição.

No entanto, a reprodução de uma marca de fato de terceiros, especialmente quando é idêntica ou substancialmente idêntica a tal marca anterior, colide com o efeito excludente da marca de fato, quando: 
ISSN ELETRÔNICO 2316-8080

DENIS BORGES BARBOSA

(a) ocorre no mesmo mercado, de especialidade, geográfico e ao mesmo tempo;

(b) é suscetível de causar confusão ou associação do público pertinente.

Como marcam os precedentes, não há qualquer justificativa de direito em copiar elementos de marcas de fato ou de direito de terceiros, quando existam muitas forma alternativas de expressar uma origem de produtos e serviços:

"4. No caso concreto, o foco do reclamo da autora é a semelhança entre as embalagens dos produtos da ré e os seus, sob dois prismas: a) o primeiro, de supostamente induzir os consumidores em erro, traduzindo um injusto desvio de mercado; b) o segundo, de parasitismo e proveito do prestígio alheio.

O perito judicial, analisando as embalagens das latas de creme de leite comercializados pelas partes, concluiu pela relativa semelhança entre os pares de produtos comparados.

O exame atento do laudo pericial revela que as embalagens de creme de leite utilizadas pela ré remetiam diretamente às embalagens da autora, que primeiro delas se utilizara e é líder de mercado.

Tenho dúvidas se o consumidor pode ser levado a erro pelas semelhanças das embalagens. Isso porque, apesar da similitude de cores e de figuras, os produtos têm as marcas "Nestlé", "Parmalat" e "Glória" ostensivas nos rótulos, que, de algum modo cumprem papel diferenciador.

Forçoso reconhecer, porém, que as evidentes semelhanças existentes não eram necessárias, nem cumpriam qualquer fim social relevante.

Pode-se até alegar que a fruta morango guarda certa associação com creme de leite. $O$ que me desagrada não é o uso isolado da fruta, mas sim somado à similitude de cores azul e branco, o jorro do leite, enfim toda a composição da embalagem, que remete inegavelmente ao produto concorrente.

É notório que haveria uma associação entre os produtos, decorrente da similitude da disposição das cores e imagens entre ambos, e estou convencido que essa parecença foi deliberadamente desejada pela ré, ao alterar as embalagens, atendendo a estudo de mercado.

Fato incontroverso, mais, que as rés alteraram suas embalagens, após pesquisa de mercado. Não vejo razão plausível para a mudança, aproximando as novas embalagens daquela idealizada e construída pela líder de mercado.

A proteção à marca deve ser vista sob duplo aspecto. Um é evitar o erro, a confusão do consumidor; outro é evitar o parasitismo, o enriquecimento sem causa à custa do prestígio de marca alheia." (TJSP, Ac 994.07.115467- 
ISSN ELETRÔNICO 2316-8080

DOS EFEITOS DA DECLARAÇÃO DE DISTINTIVIDADE ADQUIRIDA

5, 4o Câmara de Direito Privado do Tribunal de Justiça de São Paulo, Des. Francisco Loureiro, 25 de fevereiro de 2010).

Neste outro, a noção da ilicitude da imitação não eficiente, da cópia que visa simplesmente à associação e ao uso de prestígio alheio:

O objeto de sua crítica é que a designação Real adotada nos produtos comercializados pelas rés importa em comércio parasitário, em usurpação de prestígio alheio, eis que há notória semelhança ortográfica e semântica com a marca registrada da autora Royal - designação para a qual obteve registro de marca junto ao INPI.

Evidente que REAL e ROYAL são palavras que se assemelham tanto na ortografia quanto no significado. As semelhanças talvez não tenham o condão de iludir os consumidores, porém forçoso reconhecer que também não se mostram necessárias, nem cumprem qualquer fim relevante.

É notório que há uma associação entre os produtos, decorrente da similitude na identidade de baralhos e similitude de suas marcas. Um produto novo no mercado e de preço muito inferior remete a outro reconhecido e consagrado pelo mercado.

Destaco que a natureza do produto - baralho - pode levar a certa confusão entre consumidores. Não se trata de bem adquirido costumeiramente, mas que, ao contrário, costuma ser usado ao longo de anos. Razoável supor que o consumidor, que esporadicamente adquire baralhos e tem gravada na mente a tradicional marca Royal, tome o produto Real pelo outro, ou como uma segunda linha da mesma fabricante, a preços mais acessíveis.

O caso seria, então, não propriamente de reprodução, mas sim de imitação da marca, sem cópia servil, mas com semelhança suficiente para gerar confusão prejudicial ao titular com precedência de uso e aos próprios consumidores.

Sabido que uma das formas mais sutis de imitação é a ideológica, qual seja, "a que procura criar confusão com a marca legítima por meio da ideia que evoca ou sugere ao consumidor. Há marcas que despertam a ideia do produto a que se aplicam ou de alguma de suas qualidades, ou que sugerem uma ideia qualquer, sem relação direta com o produto assinalado" Gama Cerqueíra, Tratado da Propriedade industrial, 2a. Edição RT, p 918). Assinala o autor que em tal hipótese, "o emprego da marca, que desperte a mesma ideia da marca legítima, mesmo que materialmente diversa, pode estabelecer confusão no espírito do consumidor, induzindoo em erro".

Como constou de notável voto do Des. Énio Zuliani (TJSP, Apelação Com Revisão 2813834200) "a segurança de um aparato diferenciador de produtos não está baseada somente na necessidade de proteger pessoas incultas e ignorantes, mas, sim, na regulamentação da atividade construtiva, evitando que cópias e plágios fiquem imunes diante dos prejuízos das marcas notórias e vencedoras. 
Embora a ética do comércio permita abrandar conceitos, para que o rigor no exame das iniciativas produtivas não emperre a máquina de investimentos, fundamental para a circulação da riqueza, não pode ser tolerada a deslealdade que, em algumas vezes, é exteriorizada pela cópia de produtos estigmatizados pela atividade da empresa concorrente".

Pouco provável, diante da infinita variedade de nomes, que a ré tenha escolhido exatamente o termo REAL para designar seu produto, açambarcando, de modo direto ou indireto, o prestígio da marca concorrente.

Este parentesco existente entre as denominações dos produtos concorrentes certamente contribui para um injusto proveito à marca do novo entrante, cuja qualidade seria associada ás dos produtos da autora.

(TJSP, AC 459.514.4/3-00, Quarta Câmara de Direito Privado do Tribunal de Justiça do Estado de São Paulo, Des. Ênio Santrelli Giuliani, 27 de agosto de 2009).

Pela terceira vez, ainda o Tribunal paulista, perguntando: para que imitar, senão para confundir?

As circunstâncias do caso concreto reforçam a impressão do parasitismo. A marca "Amor aos Pedaços" goza de inegável apelo e prestígio junto ao público em geral, fruto de anos de investimentos e cuidado na elaboração e vendas de bolos e doces. Pouco provável, diante da infinita variedade do léxico, que a ré, ao inaugurar doceria no interior de um shopping Center a menos de sessenta quilômetros de São Paulo, tenha escolhido o nome e a marca "Delícias em Pedaços" sem o propósito de beneficiar, de modo direto ou indireto, do prestígio da marca concorrente. (TJSP, AC 396.623.4/2-00, Quarta Câmara de Direito Privado do Tribunal de Justiça do Estado de São Paulo, por votação unânime, julgamento 2 de abril de 2009).

Essencialmente, ao reprimir a imitação não necessária, mas simplesmente parasitária, o direito veda apenas a desproporção ilícita no exercício do direito fundamental de cópia. Imita-se licitamente, para aumentar a eficiência da economia, em favor do público. Mas não há como coonestar a imitação que apenas aproveita o prestígio alheio, sem consistir o exercício de competência própria:

VISTOS, relatados e discutidos estes autos, ACORDAM os membros integrantes da Segunda Câmara Cível do Tribunal de Justiça do Estado do Paraná, por unanimidade de votos, em dar provimento parcial ao recurso, para dispor que a apelada pode usar a palavra PHILIPS, desde que o faça sem destaque, sem menção a serviços com peças originais e sempre com a ressalva expressa de que se trata de serviço não autorizado. (...)

As publicidades inseridas nos catálogos telefônicos, a fls. 28, 29 e 30, trazem a logomarca PHILIPS bem destacada, em caixa-alta, letras brancas 
com fundo escuro, em retângulo e o nome da prestadora de serviços logo a cima, em letras bem menores e sem qualquer destaque. Abaixo da palavra PHILIPS, em letra bem menor, vem outra logomarca: PHILCOHITACHI. Na publicidade de fls. 29, aliás, sequer consta o nome da empresa prestadora de serviços.

Trata-se de publicidade indevida pela sua desproporção. O seu destaque maior é sobre o produto, assinalando-se de forma bem secundária quem presta o serviço. É uma forma de parasitar no crédito alheio e induzir o público à confusão.

As oficinas autorizadas pela apelada atendem a minuciosos padrões de controle de qualidade, com técnicos especialmente treinados, o emprego de peças originais e a garantia de serviços prestados (ver. fls. 16/24). Há uma extensa rede de atendimento à clientela.

É evidente que não se pode impedir que outras empresas atuem no setor. Mas não podem fazê-lo sob disfarce que iluda os consumidores. A apelada pode usar a palavra PHILIPS, como disposto na sentença, desde que o faça sem destaque e sempre com a ressalva expressa de que se trata de serviço não autorizado. A publicidade "serviços com peças originais" também pode induzir o consumidor a pensar que se trata de oficina especializada, razão pela qual deve também ser proibida. Esta proibição se estende a qualquer impresso da apelada, como notas fiscais, duplicatas, contratos e todas as formas de publicidade. (Tribunal de Justiça do Paraná, Apelação Cível No 50.248-5, da Comarca de Curitiba - $7^{a}$ Vara Cível. Apelante : Philips do Brasil Ltda. Apelado : TV Tec Assistência Técnica. Relator: Juiz de Alçada Convocado Munir Karam).

Assim cabe responder: quando terceiro, utilizando-se de marca figurativa substancialmente igual, em atividade igual, emprega em suas atividades a parte nominativa objeto de apostilamento da marca anterior, comete concorrência desleal.

\section{Apostilamento do registro posterior}

Note-se qual o efeito do apostilamento no caos em que esse se fundamente na falta de distintividade: é declarar que o elemento tido como não distintivo não terá exclusividade.

Ocorre, que tal apostilamento, simultaneamente, licita o uso não exclusivo por parte do titular do registro apostilado. Com efeito, se o elemento apostilado pertencesse a terceiros, a apostila - se houvesse - só poderia ser: o registro não inclui o direito de uso de XYZ". Com efeito, uma coisa é o uso não exclusivo, ou seja, uso concorrente de elementos genéricos; outra é o dever de não usar elemento de marca de terceiros.

Assim, deve ser declarada a nulidade do elemento apostilado como "sem direito ao uso exclusivo de ...", quando nenhum uso, concorrente ou não, é 
permitido de marca ou elemento de marca de terceiros. Entre essas hipótese, está a do elemento protegido pelo art. 124, XXIII do CPI/96.

Exatamente o mesmo ocorre se essa marca de fato, protegida pela Exceção Pouillet, foi objeto de aquisição subsequente de distintividade (secondary meaning). Uma vez marca de fato, tenha essa distintividade originária, ou subsequente, será sempre objeto de proteção do art. 124, XXIII, sempre que o depositante da marca júnior "evidentemente não podia deixar de conhecer da marca anterior".

Publicado no dia 27/06/2014

Recebido no dia 16/06/2014

Aprovado no dia 18/06/2014 